http://doi.org/10.35784/iapgos.2646

\title{
THE METHOD OF OBTAINING THE SPECTRAL CHARACTERISTICS OF THE SCANNING PROBE MICROSCOPE
}

\author{
Mariia Kataieva, Vladimir Kvasnikov \\ National Aviation University, Ukraine, Kyiv \\ Abstract. The article discusses methods and algorithms for digital processing and filtering when carrying out nano-measurements using a scanning probe \\ microscope. The paper discusses frequency methods for improving images, in particular, the use of the Fourier transforms with various filtering methods \\ to improve the quality of the resulting image. Stable computational algorithms have been developed for transforming discrete signals based on the Fourier \\ transform. Methods for the interpretation of the numerical results of the discrete Fourier transform in such packages as Matlab, MathCad, Matematica are \\ presented. It is proposed to use a window transform, developed based on the Fourier transform, which makes it possible to single out the informative \\ features of the signal and to reduce the influence of the destabilizing factors that arise when processing signals from a scanning gold microscope in real \\ conditions.
}

Keywords: nano-measurement, digital signal processing, scanning probe microscope, Fourier transform

\section{SPOSÓB UZYSKANIA CHARAKTERYSTYKI WIDMOWEJ SONDY SKANUJĄCEJ MIKROSKOPU}

Streszczenie: $W$ artykule omówiono metody i algorytmy cyfrowego przetwarzania i filtracji podczas nano-pomiarów z wykorzystaniem mikroskopu z sonda skanujaca. Badane sa metody korekcji częstotliwości obrazu, w szczególności wykorzystanie transformaty Fouriera z różnymi metodami filtracji w celu poprawy jakości otrzymanego obrazu. Opracowano stabilne algorytmy obliczeniowe do konwersji sygnatów dyskretnych na podstawie transformaty Fouriera. Przedstawiono metody interpretacji numerycznych wyników dyskretnej transformaty Fouriera $w$ takich pakietach jak Matlab, MathCad, Matematica. Proponuje się zastosowanie transformacji okienkowej opracowanej na podstawie transformaty Fouriera, która pozwala wyodrębnic charakterystyke informacyjna sygnału $i$ zmniejszyć wplyw czynników destabilizujacych wystęujacych podczas przetwarzania sygnału z mikroskopu z sondą skanująca $w$ warunkach rzeczywistych.

Słowa kluczowe: nano-pomiar, cyfrowe przetwarzanie sygnału, mikroskop z sondą skanującą, transformata Fouriera

\section{Introduction}

In recent years, the study of submicron, nano-, and cluster materials has developed rapidly due to existing and potential applications in many technological fields, such as electronics, catalysis, magnetic data storage, structural components, etc.

The study of nanoscale structures (nanostructures) belongs to the direction of nanotechnology. The important components of this scientific and technical direction are the development and study of nanostructured materials, the study of the properties of the obtained nanostructures under various conditions.

Many countries are actively searching for optimal methods for measuring nanomaterials. The results of these methods are increasingly demanding. The main ones are accuracy, versatility, and high-speed calculations. Unfortunately, optimal methods have not yet been developed by which it would be possible to analyze different types of nano-materials with equal success, taking into account the above requirements [13].

One of the most modern methods for measuring the characteristics of materials and diagnosing the features of small-sized systems is electron and scanning probe microscopy (SPM). With the use of this device and the developed techniques, many interesting scientific results have been obtained concerning the mechanical, electrical, and tribological properties of new structural materials and unique products. The purpose of microscopic examination of solids using scanning probe microscopy is to obtain an enlarged image of the surface.

SPM images, due to the specificity of the method, usually contain noise. This is due to the vibration of the probe relative to the sample, acoustic interference, noise from electrical equipment, which are always present when measuring weak signals. Image distortions are also introduced due to thermal drift of the probe relative to the sample, nonlinearity, and creep in the piezoelectric elements from which the scanner is made. In this regard, to obtain high-quality SPM images and conduct their quantitative analysis, it is necessary to improve existing ones and develop new methods for the digital processing of these images.

\section{Analysis of existing methods for studying nanostructures}

Thus, several methods of analysis are often used to analyze the structure of nanomaterials - fractal, textural, and classical amplitude method. Currently, the most popular fractal methods of analysis, but these methods have low efficiency in the study of materials with complex relief. This is because the main characteristic of fractals - fractal dimension [13, 18], has a direct dependence on the complexity of the relief, which is obtained by the interaction of filler particles and the source material. Other commonly used methods of image analysis are methods based on working with the matrix of the image itself, the so-called. amplitude methods [12].

Such as calculating the areas of figures are in the image, brightness differences, highs, and lows, averages, etc. However, there is an even bigger drawback. In matters relating to the analysis of images obtained by optical methods, there is an error related to the quality of the image and the conditions under which it was obtained. So changing the brightness or sharpness of the image leads to a significant change in the result.

These methods of analysis can be applied to images that are the result of the use of electronic, X-ray, and other non-optical methods of studying the structure of the material. Digital filtering of noisy signals and images is important in solving a wide range of scientific and technical problems. Such tasks arise, in particular, in communication technology to improve the quality of reception of transmitted messages $[13,18]$.

Thus, several methods of analysis are often used to analyze the structure of nanomaterials - fractal, textural, and classical amplitude method. Currently, the most popular fractal methods of analysis, but these methods have low efficiency in the study of materials with complex relief. This is because the main characteristic of fractals - fractal dimension [13, 18], has a direct dependence on the complexity of the relief, which is obtained by the interaction of filler particles and the source material.

Other commonly used methods of image analysis are methods based on working with the matrix of the image itself, the so-called. amplitude methods [12]. Such as calculating the areas of figures are in the image, brightness differences, highs, and lows, averages, etc. 
However, there is an even bigger drawback. In matters relating to the analysis of images obtained by optical methods, there is an error related to the quality of the image and the conditions under which it was obtained. So changing the brightness or sharpness of the image leads to a significant change in the result.

These methods of analysis can be applied to images that are the result of the use of electronic, X-ray, and other non-optical methods of studying the structure of the material. Digital filtering of noisy signals and images is important in solving a wide range of scientific and technical problems.

Such tasks arise, in particular, in communication technology to improve the quality of reception of transmitted messages [13, 18]. Traditionally, approaches that use Fourier transforms have been used to clear information messages from interference.

\section{Signal filtering using Fourier transforms}

The most convenient from the point of view of the organization of processing and a natural way of sampling is the representation of signals in the form of samples of their values (samples) in separate, regularly located points $T_{\partial}=\Delta t$. In practice, the sampling operation is performed by measuring the values of the signal using a sensor, the action of which can be described as a convolution with a core $\gamma_{\partial}=(t)$ :

$$
u(k \Delta t)=\int_{-\infty}^{\infty} u(t) \gamma_{\partial}(t-k \Delta t) d t
$$

set of values $\{u(k \Delta t)\}$ is a discrete representation of the signal. The core $\gamma_{\partial}(t)$ is called the sampling aperture. Recovery of a continuous signal from approximate values $\{u(k \Delta t)\}$ performed by interpolation

$$
\sum_{k} u(k \Delta t) \gamma_{\partial}(t-k \Delta t) \approx u(t)
$$

using the interpolating function $\gamma_{b}(t)$, which is called the recovery aperture.

If we proceed only from the accuracy of the approximation, then there is an important class of signals and the corresponding basic functions for which the distributions (1) and (2) are accurate. These are signals whose Fourier spectrum $U(f)=F\{u(t)\}$ non-zero only within a limited area of the detection area (signals with a limited spectrum). Let the signal sector differ from zero in the interval $\left(\frac{1}{2 \Delta t}, \frac{1}{2 \Delta t}\right)$, that is

$$
\begin{gathered}
U(f)=U(f) \operatorname{rect}\left(f \Delta t+\frac{1}{2}\right) . \\
\operatorname{rect}(a)=\left\{\begin{array}{lr}
1, & 0 \leq \alpha \leq 1 \\
0, & \text { in other cases }
\end{array}\right.
\end{gathered}
$$

For such signals, the sampling and recovery bases are formed from the reference functions:

$$
\begin{gathered}
\gamma_{\partial}(t)=\left(\frac{1}{\Delta t}\right) \sin c\left[\frac{\pi(t-k \Delta t)}{\Delta t}\right] \\
\gamma_{b}(t)=\sin c\left[\frac{\pi(t-k \Delta t)}{\Delta t}\right],
\end{gathered}
$$

a (1) i (2) go into exact equations:

$$
\begin{aligned}
& u(k \Delta t)=\frac{1}{\Delta t} \int_{-\infty}^{\infty} u(t) \sin c\left[\frac{\pi(t-k \Delta t)}{\Delta t}\right], \\
& u(t)=\frac{1}{\Delta t} \sum_{-\infty}^{\infty} u(k \Delta t) \sin c\left[\frac{\pi(t-k \Delta t)}{\Delta t}\right],
\end{aligned}
$$

These relations are called the reference theorem. Equation (5) means that the samples of the signal are its values in points $\{k \Delta t\}$, obtained after passing the signal through an invariant to the offset "ideal" filter with pulse and frequency characteristics:

$$
\begin{aligned}
h_{\partial}(t)= & \gamma_{\partial}(t)=\left(\frac{1}{\Delta t}\right) \sin c\left(\frac{\pi t}{\Delta t}\right), \\
& H_{\partial}(f)=\operatorname{rect}\left(f \Delta t+\frac{1}{2}\right) .
\end{aligned}
$$

Equation (6) means that the procedure for restoring a continuous signal from its samples $u\{k \Delta t\}$, can be represented as the transmission through an ideal low-pass filter (7), (8) of a continuous signal of the form

$$
u_{1}(t)=\sum_{-\infty}^{\infty} u(k \Delta t) \delta(t-k \Delta t)
$$

whose spectrum $U_{1}(f)$ is periodically extended with the period $\frac{1}{\Delta t}$ spectrum $U(f)$ signal $u(t)$ :

$$
U_{1}(f)=\sum_{m=-\infty}^{\infty} U\left(f-\frac{m}{\Delta t}\right)
$$

Indeed, such filtering spectrum $U_{1}(f)$ multiplied by the frequency response of the filter (8), which allocates only one period of the spectrum corresponding $m=0$ equal to the signal spectrum $u(t)$. Periodic continuation of the spectrum (10) is possible if the rasterization step $\Delta t$ is less than or equal to the inverse of the length of the spectrum. Otherwise, there is an overlap of adjacent periods of the signal spectrum, $u_{1}(t)$ and with an ideal low-pass filter, it is impossible to select the signal spectrum in its pure form (Fig. 1).

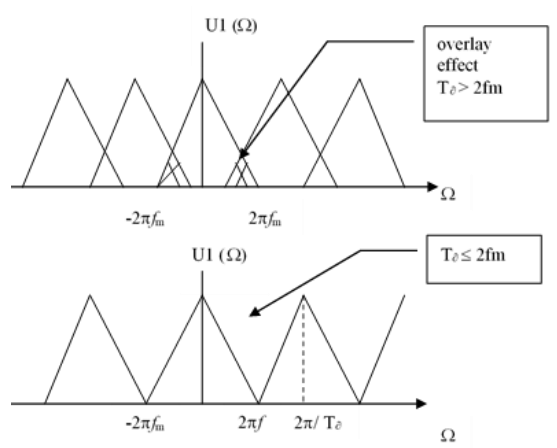

Fig. 1. Overlapping of adjacent periods of the signal spectrum

Although as a result of thinning, each of the time series will be characterized by a frequency range twice less than the signal before filtering, the presence of two sequences (at the output of each filter) allows you to uniquely restore the output signal in reverse conversion. The use of digital low-pass filters in the receiving device reduces the level of additive noise present in the signal transmitted over the communication channel.

Depending on the requirements for receiving information messages and the spectral composition of the signal and noise can also be used band-pass or band-barrier filters [10, 12]. But even though the mathematical apparatus of Fourier transform is an important and useful tool for practical research, it has some limitations.

Thus, filters based on Fourier transforms do not effectively eliminate isolated features of signals. Since this transformation uses infinitely oscillating harmonic functions, information about the isolated features of the signal is contained in all conversion factors.

These problems can be partially solved by applying the window Fourier transform, which allows you to limit the range corresponding to the selected time window.

\section{Application of window Fourier transform}

The time interval of the signal is divided into subintervals and the conversion is performed sequentially for each subinterval separately. Thus, the transition to the frequency-coordinate representation of the signals, while within each subinterval the signal is "considered" stationary. The result of the window transformation is a family of spectra, which reflects the change in the spectrum of the signal at intervals of the shift of the transformation window.

This allows you to select on the coordinate axis and analyze the features of non-stationary signals. The size of the window function media $\mathrm{w}(\mathrm{t})$ is usually set comparable to the stationary interval of the signal. In essence, such a transformation of one nonlocalized basis is divided into some bases localized within the function $\mathrm{w}(\mathrm{t})$,

Window conversion is performed according to the expression:

$$
S\left(\omega, b_{k}\right)=\int_{-\infty}^{\infty} s(t) \cdot \omega\left(t-b_{k}\right) \cdot e^{-j \omega t} d t
$$

where is the function $w(t-b)$ is a function of the transformation shift window from coordination $t$, where the parameter $b$ sets fixed offset values.

When shifting windows with a uniform step, the values of $b_{k}$ are taken equally $b_{k}=k \Delta b$. Both the simplest rectangular window and special weighted windows (Bartlett, Gauss, etc.) which provide small distortions of a spectrum at the cutting of window segments of signals (neutralization of the Gibbs phenomenon) can be used as transformation windows. 
An example of a window conversion for a non-stationary signal at a high noise level is shown in Fig. 2. According to the signal spectrum, it is possible to judge the presence of harmonic oscillations in its composition at three frequencies, to determine the relationship between the amplitudes of these oscillations, and to specify the locality of oscillations in the signal interval.

The signal is the sum of three consecutive radio pulses with different frequencies without pauses, with a signal-to-noise ratio close to 1 . The window function wi is given with an effective window width $b \cong 34$ and a full-size $M=50$.

The frequency step $\Delta \omega=0.1$ is set for the results. slightly higher than the actual resolution $\frac{2 \pi}{M}=0.126$.

The coordinate resolution of the window transformation is determined by the width of the window function and is inversely proportional to the frequency resolution. When the width of the window function is equal to $b$, the frequency resolution is determined by the value $\Delta \omega=\frac{2 \pi}{b \Delta \omega}$.

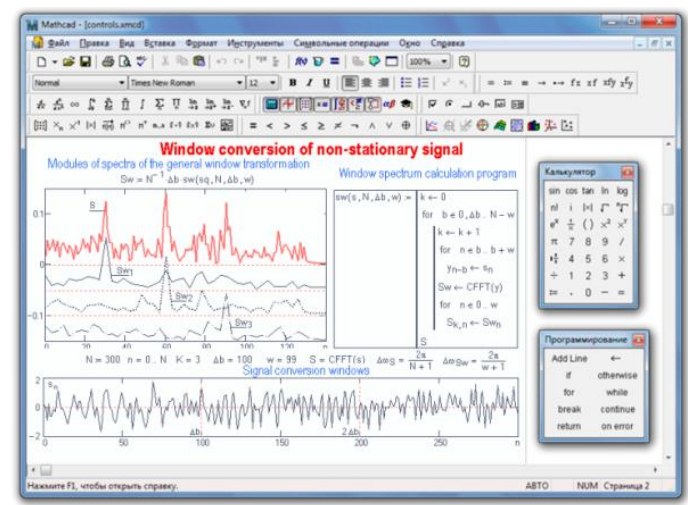

Fig. 2. Example of a conversion window for a transient signal at the high

At the required value of the frequency resolution $\Delta \omega$ accordingly, the width of the window function must be equal to $b=\frac{2 \pi}{\Delta \omega}$. For the window Fourier transform, these restrictions are fundamental. Yes, for Fig. 2 when the size of the data array $N=300$ and the width of the window function $\Delta b=100$ the frequency resolution of the conversion results decreases $\frac{N}{\Delta b}=3$ times compared to the original data and graphs $S\left(\omega, b_{k}\right)$ $S\left(n \Delta \omega_{-} s\right)$ on the coordinate $n$ for visual comparison with the graph $\Sigma(v \Delta \omega \Sigma)$ are constructed with a step on the frequency $\Delta \omega_{S_{\omega}}=3 \Delta \omega_{S}$, that is, at points $n=0,3,6, \ldots, N$.

However, this option has significant drawbacks - it is excessive, and many coefficients of decomposition of wavelet functions contain information that is duplicated in other coefficients. Such redundancy is not always a disadvantage, but it leads to a significant increase in computational time due to the lack of effective fast calculation algorithms of the non-stationary random process.

It is also worth remembering that when calculating the value of any fractal dimension, the selected step (window size) has a great influence, by which the image is calculated. For example, the fractal dimension of the same image calculated by a window of $5 \times 5$ dots will be less than when using a window of size $3 \times 3$.

Frequency-time window conversion is used to analyze non-stationary signals if their frequency composition changes over time. The window transformation function (11) can be translated into a two-dimensional version with independent variables in time and frequency:

$$
S(t, \omega)=\int_{\tau} s(t-\tau) \cdot \omega(\tau) \cdot e^{-j \omega t} d \tau,
$$

In Fig. 3 shows an example of calculation and presentation (module of the right part of the main range of the spectrum) of the frequency-time spectrogram for a discrete task of the input signal $S q(n)$.

To ensure the operation of the window function throughout the signal interval, the initial and final conditions of the calculations were set (continuation of both ends of the signal by zero values at $\mathrm{M}$ points).

As can be seen from the results of calculations, the window conversion allows you to highlight the informative features of the signal and time and frequency. The localization resolution is determined by Heisenberg's uncertainty principle, which states that it is impossible to obtain an arbitrarily accurate discrete representation of a signal.

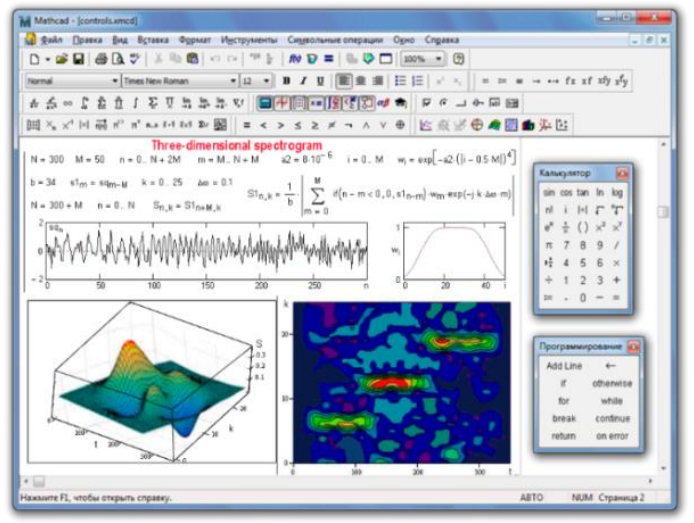

Fig. 3. An example of calculating and presenting a time-frequency spectrogram for a discrete problem of an input signal

The larger the window, the better the temporary resolution, but worse the frequency, and vice versa (Fig. 4).

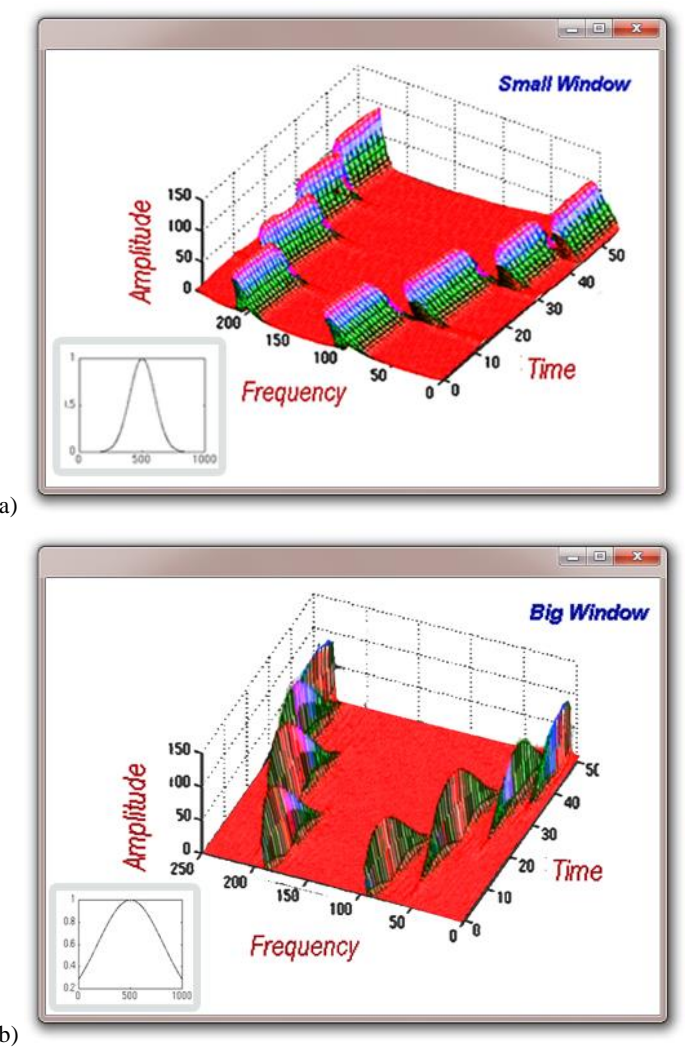

Fig. 4. An example of frequency-time window conversion of a signal consisting of 4 disjoint intervals: a) Small Window, b) Big Window

Figure 4 shows an example of frequency-time window conversion of a signal consisting of 4 disjoint intervals, each of which is the sum of two harmonics of different frequencies. The Gaussian function of different widths is applied as windows.

The narrow window provides better temporal resolution and clear fixation of the boundaries of the intervals, but wide frequency peaks within the intervals. A wide window opposite clearly indicates the frequency of intervals, but with overlapping boundaries of time intervals. When solving practical problems, you have to choose a window to analyze the entire signal, while different parts of it may require the use of different windows. 
If the signal consists of distant frequency components, then you can sacrifice spectral resolution in favor of time, and vice versa.

\section{Illustrative examples}

Using the analytical mechanism, areas with different textures were selected, each type of texture was assigned its unique index. This index, when creating the texture of the image, acts as a label for a particular color, we have the opportunity for both the visual analysis of the texture picture and mathematical analysis of the matrix of indexes.

Going from the original image to its texture map, it is possible to level the contribution of external factors affecting the resulting image. Fig. 5 shows an image obtained using an electron microscope, as well as its texture map. In the future, based on the resulting texture, the Fourier transform is calculated, which allows you to select the main peak values, that distinguish images with different fillers and concentrations.
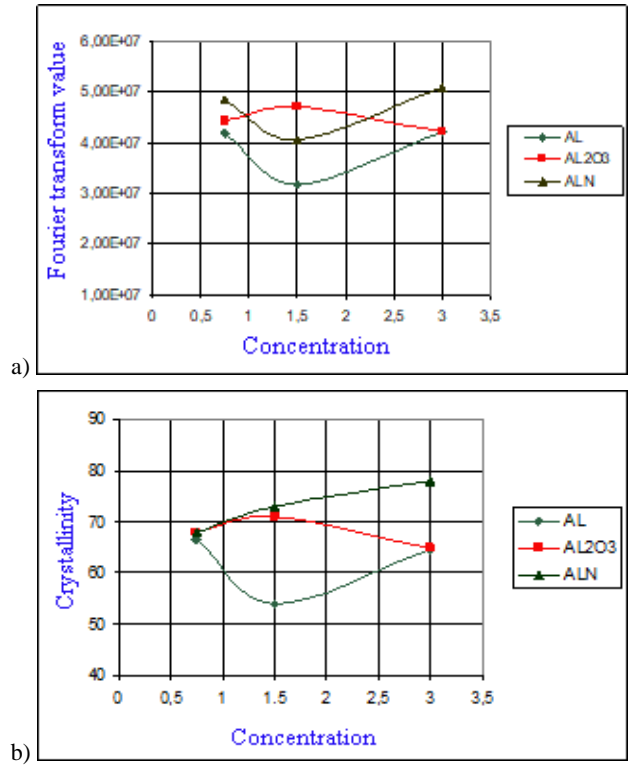

Fig. 5 a) Dependences of the value of the Fourier transform on the concentration and $b)$ the dependence of the degree of crystallinity on the concentration

The meaning of the Fourier transform is that it allows us to distinguish from the textural picture of the amplitudes and their periodicity, which characterize the distribution and magnitude of texture variability. From a physical point of view, this transformation allows us to assess how much the structure of the object changes, and to link this change with the physicochemical parameters that cause this change.

The results of evaluations with textured cards (quantified by the value of the Fourier transform) were compared with the values of the degree of crystallinity obtained for the selected objects of study. It turned out that the nature of the dependences on the concentration of the value of the Fourier transform is similar to the pattern of changes in the concentration of the degree of crystallinity of the studied objects (Fig. 5).

Since the degree of crystallinity directly affects the structure of the material, we can assume that the value of the Fourier transform responds to structural changes.

\section{Conclusions}

In the course of analyzing the methods and algorithms for digital processing and filtering of signals during nanomeasurements using a scanning probe microscope, frequency methods of image enhancement were studied. It is proposed to use a window transform, developed based on the Fourier transform, which makes it possible to single out the informative features of the signal and reduce the influence of destabilizing factors arising from the processing of signals from a scanning gold microscope in real conditions. The use of the Fourier transform allows both a qualitative analysis of the spectrum and its quantitative interpretation.

Analysis data show that the method not only depends on the degree of crystallinity of the polymer but also distinguishes materials by their properties.

\section{References}

[1] Addison P. S.: Secondary transform decoupling of shifted nonstationary signal modulation components: application to photoplethysmography. Int. J. Wavelets Multires. Inf. Proc. 2, 2004, 43-57.

[2] Falvo M. et al. The nanomanipulator: A teleoperator for manipulating materials at the nanomerter scale. Proc. of Int. Symp. On Science and Technology of Atomically Engineered Materials, 1996, 579-586.

[3] Hyon C. K. et al.: Application of atomic-force-microscope direct patterning to selective positioning of InAs quantum dots on GaAs. Applied Physics Letters $77,2000,2607-2609$.

[4] Ito K. J. et al.: Servomechanism for locking scanning tunneling microscope tip over surface nanostructures. Rev. of Sci. Inst. 71(2), 2000, 420-423.

[5] Iwasaki H., Yoshinobu T., Sudoh K.: Nanolithography on $\mathrm{SiO} / \mathrm{Si}$ with a scanning tunneling microscope. Nanotechnology 14, 2003, 55-62.

[6] Majumdar A. et al.: Nanometer-scale lithography using the atomic force microscope. Applied Physics Letters 61, 2002, 2293-2295.

[7] Mokaberi B., Requicha A. A. G.: Drift compensation for automatic nanomanipulation with scanning probe microscopes. IEEE Trans. on Automation Science and Engineering 3(3), 2006, 199-207.

[8] Mokaberi B., Requicha A. A. G.: Towards automatic nanomanipulation drift compensation in scanning probe microscopes. IEEE Int. Conf. on Robotics and Automation, New Orleans, LA, 2004.

[9] $\mathrm{Ohji} \mathrm{H}$ et al: Fabrication of a beam-mass structure using single-step electrochemical etching for micro structures (SEEMS). J. Micromech. Microeng. 10, 2000, 440-444

[10] Roth S., Dellmann L., Racine G. A., de Rooij N. F.: High aspect ratio UV photolithography for electroplated structures. J. Micromech. Mecroeng. 9, 2009, $105-108$.

[11] Sahoo D. R. et al.: Transient signal based sample detection in atomic force microscopy. Applied Physics Letters 83(26), 2003, 5521-5523.

[12] Said R. A.: Microfabrication by localized electrochemical deposition: experimental investigation and theoretical modeling. Nanotechnology 15, 2004 867.

[13] Salapaka S., De T.: A new sample-profile estimate for faster imaging in atomic force microscopy. Proceedings of the American Control Conference, Boston, MA, 2004.

[14] Salapaka M. V. et al.: Multimode noise analysis of cantilevers for scanning probe microscopy. Journal of Applied Physics 81(6), 1997, 2480-2487.

[15] San Paulo A., Garcia R.: Tip-surface forces, amplitude and energy dissipation in amplitude-modulation (tapping mode) force microscopy. Physical Review B. 64, 2002, $041406(1-4)$.

[16] Sebastian A. et al.: Robust control approach to atomic force microscopy. Proceedings of the IEEE Conference on Decision and Control, Hawai, 2003.

[17] Staub R. at al.: Drift elimination in the calibration of scanning probe microscopes. Rev. Sci. Inst. 66(3), 1995, 2513-2516.

[18] Yang Q., Jagannathan S.: Nanomanipulation using atomic force microscope with drift compensation. Proceedings of the 2006 American Control Conference, Minneapolis, Minnesota, USA, 2006.

[19] Yang S. et al.: Block phase correlation-based automatic drift compensation for atomic force microscopes. IEEE Int. Conf. on Nanotechnology, Nagoya, Japan, 2005.

[20] Yaseen A. S. at al.: Speech signal denoising with wavelet-transforms and the mean opinion score characterizing the filtering quality. Proc. SPIE. 9707, 2016, 970719.

Prof. Vladimir Kvanikov

e-mail:kvp@nau.edu.ua

Professor of the Department of Computerized Electrical Systems and Technologies, National Aviation University, Kyiv, Ukraine.

http://orcid.org/0000-0002-6525-9721

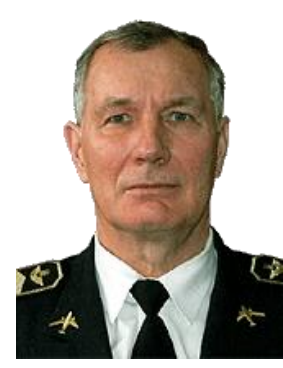

Ph.D. Mariia Kataieva

e-mail: mariia.kataeva@gmail.com

Associate professor of the Department of Computeized Electrical Systems and Technologies, National Aviation University, Kyiv, Ukraine

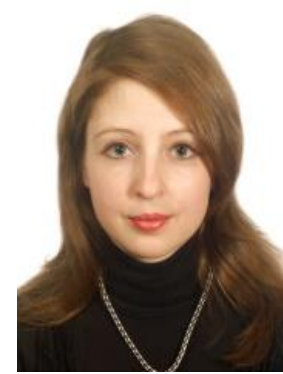

